\title{
LA MISIÓN Y LA IGLESIA
}

DOI: https://doi.org/10.52039/seminarios.v52i180.663

Autor: Román Sánchez Chamoso. Sacerdote Operario. Profesor de Teología en Caracas y en Ciudad Bolivar de Venezuela.

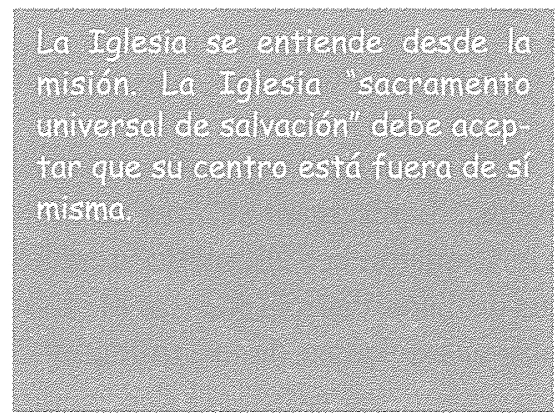

La Iglesia se entiende desde la misión, que es elemento esencial de su vocación. La teología actual habla de misión como fundamento y finalidad de la Iglesia, como causa explicativa de su razón de ser a la luz del concilio Vaticano II. El giro que significa este planteamiento se basa en la autocomprensión que la Iglesia tiene de sí misma al definirse como "sacramento universal de salvación"1, que ahuyenta todo eclesio-centrismo: la Iglesia tiene su centro fuera de sí misma, no existe para sí, sino para el Evangelio o para la misión ${ }^{2}$.

1 Cf. LG 48b; AG la. Otras expresiones similares: LG 1; 9b-c; $42 \mathrm{c}$.

2 El planteamiento podría formularse en estos términos: de una Iglesia introvertida a una Iglesia extrovertida: cf. S. DIANICH, Iglesia extrovertida. Investigación sobre el cambio de la eclesiología contemporánea, Sigueme, Sal amanca 1991. 
Este trabajo constará de cuatro partes fundamentales.. a) La misión en perspectiva trinitaria y vocacional; b) La trayectoria teológica hasta el Vaticano II; c) El viraje del concilio; d) Terminamos con una reflexión sobre la misión a partir de la encíclica "Redemptoris missio".

\section{La misión en perspectiva trinitaria y vocacional}

Antes de abordar la orientación del Vaticano II sobre la misión como definidora de la Iglesia, es oportuno esbozar algunos puntos de hondo calado teológico que ofrezcan cobertura al giro que va a operarse.

\subsection{Fundamento trinitario de la misión ${ }^{3}$}

El Vaticano II nos ofrece con toda precisión el pórtico teológico: "La Iglesia peregrinante es, por su naturaleza, misionera, pues toma su origen de la misión del Hijo y de la misión del Espíritu Santo, según el propósito de Dios Padre"(AG 2a; cf. LG 2-4; AG 2-4). Esto nos dice que todo arranca del seno de la Trinidad y de su proyecto salvador manifestado en su acción "ad extra": el Padre como fuente del designio salvador (cf. LG 2; AG 2), llevado a cabo en la misión del Hijo (cf. LG 3; AG 3) y en la misión del Espíritu Santo (cf. LG 4; AG 4). La Iglesia, por tanto, recibe una misión de cuño genuinamente trinitario que la especifica.

El Dios cristiano es un Dios misionero, el indiscutible y primer misionero, el prototipo de todo misionero cristiano. El Padre envía al Hijo. (cf. Mt 15,24; Lc 4,18.43; Jn 3,17; 5,23-24.36-37; Hech 3,26.29; Gál 4,4; 1Jn 4,9.10.14...) y al Espíritu (cf. Jn 14,26; Rom 8,15; Gál 4,6); el Padre y el Hijo envían al Espíritu (cf. Jn,14,26; 15,26; 16,7). La vida de Dios es en sí misma flujo, salida, éxodo y así se expresa un "Dios amor"(1 Jn 4,18). La vida trinitaria se realiza como "missio", como entrega al otro. Estamos, pues, ante "el fundamento trinitario de la misión, que son las misiones trinitarias. Fundamento del que arranca toda misión en el pueblo de Dios"4.

3 Cf. R.SÁNCHEZ CHAMOSO, "Las raíces trinitarias de la misión" en Misión Hoy 28(2001)9-11.

${ }^{4}$ N. SILANES, "Misión, misiones" en X. PIKAZA-N. SILANES (Dirs), Diccionario Teológico. El Dios cristiano, Secretariado Trinitario, Salamanca 1992, 879. 
Esta es también la perspectiva de los Padres de la Iglesia5. En Dios UniTrino se da estrecha correspondencia de "communio" y "missio"; la comunión que es Dios en la vida intratrinitaria se abre plenamente a la historia. Dios no queda recluido en sí mismo, sino que sale de sí para manifestarse y regalarse. De esta forma, la "communio", al dictado del amor, se convierte en "missio".

En la Trinidad se halla la última raíz de la misión de la Iglesia; la misión apostólica "se origina y se apoya, a través de la mediación histórica de Cristo, en la riqueza trascendente del misterio trinitario"6. La misiones trinitarias son el presupuesto de la condición misionera de la Iglesia: "Las mismas procesiones del Hijo y del Espíritu Santo, que penetran a la Iglesia, la constituyen en pueblo misionero"7. Más aún, "la Iglesia es como una comunicación y una extensión de la unidad misma de Dios..., una extensión y manifestación de la Trinidad"8. La Iglesia, "icono de la Trinidad"9, debe reflejar en la tierra la vida de Dios Uni-Trino que sale de sí mismo en las misiones, haciéndose así instrumento de este Dios: "La Iglesia es únicamente el instrumento de las misiones del Hijo y del Espíritu"10.

\subsection{La misión, elemento vertebrante de toda vocación cristianall}

\subsubsection{El binomio llamada-misión, constitutivo de la vocación}

La vocación entraña dos elementos: llamada y envío o misión ineludiblemente unidos en la Biblia y formando un todo. Más aún, es la misión la que define, especifica y da contenido concreto a la vocación. Así lo entiende la teología bíblica, trinitaria y eclesiológica.

5 Ibid. 881.

6 P.ROSSANO, "Teología de la misión" en Mysterium salutis IV/1 519.

${ }^{7}$ N.SILANES, a.c., 889.

8 Y.-M. CONGAR, "Ecclesia de Trinitate" en Irenikon 14 (1937) 141.

9 Cf. B.FORTE, La Iglesia, icono de la Trinidad, Sígueme, Salamanca 1992; íd., La Iglesia de la Trinidad. Ensayo sobre el misterio de la Iglesia comunión y misión, Secretariado Trinitario, Salamanca 1996.

10 N.SILANES, a.c., 889.

11 Cf. R. SÁNCHEZ CHAMOSO, "La misión, componente teológico de la vocación" en Seminarios 170(2003)509-540. 
Para perfilar mejor nuestro tema. No entendemos aquí la misión en el sentido de "hacer actividades" o de la "misión ad gentes", sino como entidad teológica y, en cuanto tal, como parte integrante de la vocación. Si se silencia esta dimensión, se corre el riesgo de hacer equivaler vocación a "profesión". La misión es un esencial componente teológico de toda vocación cristiana; no la consideramos aquí como si se tratase de una tarea posterior que se añade a la vocación ya existente previamente, sino como elemento vertebrante interno a la vocación. Pertenece, por tanto, a la esencia o naturaleza de la vocación.

Clave de nuestra metodología para exponer este punto será la relacionalidad. Haremos referencia a la Trinidad, a la Escritura, a la mente y praxis de Jesús y a la Iglesia, buscando en ellos el verdadero fundamento de nuestro planteamiento.

\subsubsection{El tema en perspectiva bíblica}

La visión bíblico-teológica nos presenta el binomio llamada-misión como un todo con dos componentes, no dos momentos sucesivos. Es la convergencia polar de dos líneas, que da como resultado una única realidad expresada en forma de binomio en los términos que lo constituyen "mutua referencia" o "mutua inmanencia".

En ambos testamentos hallamos el mismo paradigma: la vocación no es solo "llamada", sino también "envío"; la vocación es esencialmente en sí misma llamada-misión ${ }^{12}$. Esta relación intrínseca de los dos términos se nos muestra en el Nuevo Testamento (Cf. Mc 1,17; 3,13-14; 6,7; Lc 9,1-2; Jn $21,15-17 \ldots)$. Es la vocación bíblica ${ }^{13}$. No hay llamada sin envío porque es una llamada "transitiva" que no se agota en sí misma; sin envío no hay

12 Espontáneamente entendemos por vocación la "llamada" por su similitud semántica, a la que posteriormente se encarga una tarea, pero bíblica y teológicamente vocación incluye simultáneamente llamada y envío, consagración y misión. Así la entendemos en este trabajo.

13 Cf. R. SÁNCHEZ CHAMOSO, o.c., 512-517; C.M. MARTINI-A.VANHOYE, La llamada en la Biblia, S.de E.Atenas, Madrid 1983; C.M.MARTINI, La vocación en la Biblia, S.de E.Atenas, Madrid 1997; G.DEL OLMO LETE, La vocación del líder en el antiguo Israel, Universidad Pontificia, Salamanca 1973.

Para la "llamada" en la Biblia (kaléô, klésis), cf. J. ECKERT en H.BALZ-G. SCHNEIDER(Eds), Diccionario Exegético del Nuevo Testamento, I, Sígueme, Salamanca 1996. col.2165-2171; para "envío, misión"(aposté1lo) cf. J.-A.BÜHLER en Ibid., col 437-438. 
propiamente vocación, y esto referido tanto el pueblo elegido como a individuos particulares. La llamada en la Escritura está abierta hacia adelante.

La misión sigue a la llamada como la sombra al cuerpo. La misión afecta a la identidad de la persona (es llamada-enviada), modifica su destino y expresa su nueva identidad. En la Biblia, con el cambio de nombre se expresa la designación de una persona para una tarea. Recordemos el caso emblemático de Simón (cf. Jn 1,42; Mc 3,16; Mt 16,18; 1Cor 1,12; 3,$22 ; 9,5 ; 15,5 ;$ Gál 1,$18 ; 2,9.11 .14 ; 1 \mathrm{Pe} 1,1 ; 2 \mathrm{Pe} 1,1$ ), de Abraham (cf. Gén 5,17 ), de Jacob (cf. Ex 32,29) ${ }^{14}$. La nueva misión encomendada significaba el nacimiento de un nuevo ser ministerial.

La Biblia nos muestra que Dios llama al hombre y, al llamarlo, lo enrola en su designio de salvación ${ }^{15}$. Solo entonces se puede hablar propiamente de vocación. Esta misión o encargo asignado por Dios no es algo añadido a alguien que ha sido previamente llamado, a modo de un segundo momento que sigue a la llamada, sino un elemento esencial y constitutivo del ser llamado. "Llamada y misión van unidas. La respuesta (a la llamada) es la aceptación de la misión"16.

Por su parte, la teología del carisma (carisma-vocación-misión) resalta la misma concepción de la vocación: hay indisociable unión de carisma-tarea-misión, de carisma-ministerio. Unidad fundamental que ha reconocido el Vaticano II: el carisma es un don del Espíritu para la edificación de la Iglesia17. "Carisma y compromiso, vocación y misión son dos aspectos de una misma realidad teológica"18.

14 Cf. JOHN P. MEIER, Un judio marginal. Nueva visión del Jesús histórico, III: Compañeros y competidores, Verbo Divino, Estella 2003, 239.

15 Cf. J. GUILLET en X. LÉON-DUFOUR, Vocabulario de Teología Bíblica, Herder, Barcelona 1983, 962-964. "Todas las vocaciones tienen un grado común y unas dimensiones en las que concuerdan llamada, respuesta, misión, etc., al mismo tiempo que unas diferencias, que se manifiestan en los distintos medios de llamada, diversas formas de respuesta y misiones particulares" (A. GUERRA, "Vocación" en C. FLORISTÁN-J.J.TAMAYO (Eds), Conceptos Fundamentales de Pastoral, Cristiandad, Madrid 1983, 1046). "La elección temporal es siempre una elección para un servicio histórico-salvífico" (C.KRAUS, "Elección" en W.BEINERT (Dir), Diccionario de Teología Dogmática, Herder, Barcelona 1990, 233).

16 A.GUERRA, o.c., 1049.

17 Cf. L. SARTORI, "Carismas y ministerios' en L. PACOMIO et alii, Diccionario Teológico Interdisciplinar, II, Sígueme, Salamanca 1986, 9s.

${ }^{18}$ L. GONZÁLEZ QUEVEDO, "Vocación" en A. APARICIO RODRIGUUEZ- J. CANALS CASAS(Dirs), Diccionario de la Vida Consagrada, Publicaciones Claretianas, Madrid. 
Los llamados por antonomasia (apóstoles) son los enviados por antonomasia, y este envío (no sólo la llamada, que es común) especifica la vocación de cada uno. Así lo ve Pablo: "El mismo que constituyó a Pedro apóstol de los judíos, me constituyó a mí apóstol de los paganos" (Gál 2,8). Pedro y Pablo, ambos llamados por Dios, se diferencian por la misión asignada a cada uno. La misión los ha hecho tal vocacionado concreto.

El punto de vista que estamos exponiendo puede ilustrarse también desde la perspectiva trinitaria. La vida intratrinitaria es la que fundamenta la concepción de la misión como parte integrante Es la tarea al interior de la Trinidad la que fundamenta la misión como parte integrante de la vocación cristiana en cualquiera de sus modalidades. En la misión trinitaria, todas las personas divinas quedan implicadas activamente. Jesús, único que conoce al Padre, nos lo descubre como "el que no cesa nunca de trabajar" (Jn 5,17).

En síntesis: buscar en la Escritura la misión o tarea como parte constitutiva de la vocación significa recorrerla en su totalidad. Si nos ceñimos al Nuevo Testamento, encontramos que la categoría de envío es un eje trasversal que lo recorre todo: el Padre envía al Hijo, Padre e Hijo envían al Espíritu, Jesús envía a los apóstoles, éstos (la Iglesia, la comunidad, algún apóstol determinado) envían a otras personas. Una cadena de envíos que, a partir del Padre como fuente, llega a nosotros. Llamada-elección y envío-misión forman bíblicamente una unidad.

El Vaticano II ha recuperado esta línea bíblica. Es notoria su insistencia en articular "consagración" y "misión" al hilo del ejemplo de Jesús (Jn 10,36), expresándolo el diversos registros (cf. LG 28a; SC 5a;PO 2b; Sa; $7 \mathrm{a} ; 12 \mathrm{~b} ; 17 \mathrm{e}$ ), de forma que no deja lugar a dudas cuando habla de "unidad de consagración y misión" (PO 7a). El contraste con Trento es evidente. Ese Concilio, y tras él la teología tradicional, enfatizó la "consagración" del ministro ordenado y así lo focalizó hacia el culto, dejando en penumbra la misión. Este desequilibrio se subsana en el Vaticano II que, a la perspectiva cristológica y cúltica de Trento, aporta la perspectiva eclesiológica y pastoral.

\subsubsection{La misión en la mente y praxis de Jesús}

En la conciencia y en la praxis de Jesús, "llamada" y "envío" van inseparablemente unidos. Así lo comprobamos, por ejemplo, en Mc 1,17, 
donde "la llamada a Pedro y a Andrés es más que una llamada al discipulado; lo es también a participar en la misión de Jesús de reunir al Israel escatológico"19.

El mismo Jesús es denominado cabalmente "el apóstol" (Heb 3,1), "el enviado", el misionero: así se expresa su identidad (cf. Mt 10,40; Lc $10,18 ;$ Jn $6,29-57 ; 7,29 ; 13,20 ; 20,21 \ldots)$. "Si alguien puede ser llamado el primer misionero, ése es Jesús" (Martin Hengel) ${ }^{20}$.

La misión es parte constitutiva de la vocación de Jesús. En efecto, en él se dan unidas consagración y misión según su propio testimonio:"Consagrado y enviado" por el Padre, "consagrado en orden a la misión" (Jn 10,36). El Padre lo envió para una misión precisa y polivalente como refiere el Nuevo Testamento ${ }^{21}$. Tal misión o tarea es de tal modo valorada por Jesús, que argumenta frente a sus enemigos a partir de las "obras" que realiza, acción que habla a favor de su identidad en comunión con el Padre: "Realizo las obras que el Padre me encargó" (Jn 5,36). Jesús misionero, Jesús en acción, comprometido fielmente con una misión, y que encuentra en el Padre el espejo en que mirarse: "Mi Padre no cesa de trabajar; por eso yo trabajo también en todo tiempo" (Jn 5,17). El Padre es su espejo y referencia: "El Hijo hace únicamente lo que ve hacer al Padre: lo que hace el Padre, eso también hace el Hijo" (Jn 5,19), pues "yo no puede hacer nada por mi cuenta" (Jn 5,30).

Esta conciencia de Jesús se confirma y re-potencia en su praxis. Jesús es, además, "el enviado que envía". Resalta en su vida el papel de mitente, al modo como Yahvé lo es en el Antiguo Testamento. De la conciencia que Jesús tiene sobre sí mismo como enviado con una misión se pasa a la transferencia a otros que él envía (cf. Jn 10,21). Jesús llama a otras personas no solo al discipulado o seguimiento, sino también a la misión o quehacer: Para estar con él, y para enviarlos a predicar" (Mc 3,14); "por mí y por la buena noticia" (Mc 8,35; 10,29). Cuando Jesús llama a sus discípulos, vincula estrechamente "llamada" y "misión" como resaltan todos los sinópticos (cf. Mc 1;17; 3;14;6,7; Mt 4,19; 10,1.5; Lc 9,1-2; 10,1ss).

19 JOHN P. MEIER, O .c., 186 (Los subrayados son nuestros).

20 A Jesús se le identifica, sobre todo en Juan, como "el enviado":cf. 5,36-38; 6,29.57; 7,29; 10,$36 ; 11,42 ; 17.3 .8 .18 ; 20,21 \ldots$

21 La idea se expresa en diversos registros: of .Jn 3,16-17; 10,10; 11,52; Mc 3,13.15; 6,7; Mt 10,1.7; Lc 9,1-2;10,9; 19,10; Gál 4,5; 1 Tim 1,15; 1 Jn 4,9.. 
Los llamados o "segregados" es para misionar, como hace el Espíritu Santo en Antioquía: "Sepárenme a Bernabé y a Saulo para la misión que les he encomendado" (Hech 13,2; cf. 14,26-27). El Nuevo Testamento nos ofrece el paradigma y traza las líneas maestras de la teología de la vocación y de la misión"22. "Los discípulos son enviados en misión en representación del Maestro que los envía y sustituyen a éste en su propia misión"23.

\section{3. ¿Qué significa el apostolado?}

Una fiel imagen del mismo la hallamos en el término "apóstol"24. "Los apóstoles son personas a las que se ha confiado una misión que deben cumplir. Como tales, son enviados y, por consiguiente, dispersos por el mundo. Así, se les comprende como individuos que poseen un mensaje y una autoridad que nos hace recordar a la institución judía de la schaliach"25. La misión, pues, es el constitutivo del apostolado. Inspirados e imbuidos por la idea de misión, los apóstoles son un eslabón fundamental entre Cristo y la Iglesia, llamados a jugar un papel decisivo. Se nos presenta así un esquema histórico-misionero de continuidad que se desarrolla linealmente: el Padre envía a Cristo -Cristo envía a los apóstoles- los apóstoles transmiten el mensaje de Cristo fundando Iglesias y estableciendo ministerios ${ }^{26}$.

La teología hoy, al unísono con la exégesis, sostiene que el apostolado es uno de los escasos datos eclesiológicos atribuibles directamente a Jesús ${ }^{27}$.

${ }^{22}$ Cf. A. FAVALE (Dir), Vocaziorie comune e vocazioni specifíque, LAS, Roma 1981, 16167.

23 J.-A. BUHLER, a.c., col.426.

24 Cf. R. SÁNCHEZ CHAMOSO, "La misión, componente teológico de la vocación"..., 516-517.

25 I.D. ZIZIOULAS, El ser eclesial. Persona, comunión, Iglesia, Sígueme, Salamanca 2003, 186 (subrayados en el original).

26 Puede verse este esquema básico en Jn 20,21; Lc 10,16; Jn 17,7-8; Mt 28,18-20; Rom 10,13-17; 1Jn 1,1-13; 1Tim; 2Tim 2,2; Tit 1,1-5; Hech 20,17-35 cf. además 5,22; 4,4.

27 "Lo único vinculante para la Iglesia, por proceder de Jesús, es el apostolado con estructura colegial y en comunión con la cabeza" (J.I. GONZÁLEZ FAUS, Hombres de la comunidad. Apuntes sobre el ministerio eclesial, Sal Terrae, Santander 1989, 140). 


\section{Trayectoria histórico-teológica para fundamentar el ministerio} eclesial

La teología ha llevado a cabo un trabajo secular para determinar el centro o foco principal de la acción misionera de la Iglesia. Veamos ahora a grandes rasgos la trayectoria seguida, con los acentos peculiares que ha tenido en cada época.

\subsection{El dato bíblico}

\subsubsection{Jesús, bajo el prisma misional28}

La reflexión teológica debe arrancar de la figura de Jesús

Entre los nombres con que el Nuevo Testamento denomina a Jesús destaca el de El Enviado del Padre. Cristo es sacerdote por lo mismo que es enviado, el sacerdocio y la misión predicados de él coinciden. La Carta a los Hebreos otorga conjuntamente a Cristo su condición sacerdotal y misional: "apóstol y sumo sacerdote" de nuestra fe (Heb 3,1).

Ser enviado constituye la realidad última de Jesús: "Aquí vengo, oh Dios, para hacer tu voluntad" (Heb 10,7.9). El término enviado, aplicado a Jesús, no es un mero adjetivo, sino un sustantivo que expresa su cometido mesiánico.

Si atendemos a Pablo, Dios envía a su Hijo para redimir a los que están bajo la ley (cf. Gál 4,4-5; Rom 8,4). Si volvemos los ojos a Juan, Jesús se caracteriza también por la nota misional; es enviado del Padre para que el hombre se salve ${ }^{29}$. Jesús alude a sus obras para testimoniar que el Padre lo ha enviado (cf. Jn 5,36-38). El entero cap. 17 de Juan se basa en el esquema de la misión del Hijo por el Padre. En el cuarto evangelio, Jesús es básicamente el Hijo enviado. Otra variante de lo mismo en Juan es la categoría de pastor aplicada a Jesús con su evidente carga misional (cf. Jn 10,1-16). En la misma idea misional abunda la Carta a los Hebreos (cf. 13,20), la Primera Carta de Pedro (cf. 2,25) y el Apocalipsis (cf. 7,17; $12,5)$.

28 Cf. lo visto en 1.2.3.

29 Cf. más arriba Notas 20 y 21 sobre Jesús corno "el enviado". 
Jesús, llamado y enviado por el Padre, es el primer fundamento del apostolado y de la acción misional de la Iglesia. Por medio del apóstol, constituido como tal por la misión, el Resucitado continúa presente y operante en el mundo

\subsubsection{El apóstol, bajo el prisma misional}

Los apóstoles son instituidos en tales por el envío de Jesús, no por propia iniciativa. Jesús sigue la línea de la misión que nace en Dios: "Como el Padre me ha enviado, yo también os envío a vosotros" (Jn 20,21; cf. 17,18). De esta forma los constituye pastores (cf. Mt 10,6; Jn 21,15-17), son enviados para apacentar el rebaño (cf. Hech 20,28; 1Pe 5,1-4). Cristo, el enviado y el pastor por antonomasia (cf. $1 \mathrm{Pe} 2,25 ; 5,4$ ), ha hecho partícipes de su misión y de su pastoreo a los que ha elegido para ser enviados. El ministerio y el envío de los pastores representan en la Iglesia el ministerio y el envío de Cristo.

Jesús dirige una llamada particular a algunos para confiarles, también de modo particular, la prolongación de su misión ${ }^{30}$ : "Llamó a los que él quiso... Designó entonces a Doce, a los que llamó apóstoles, para que estuvieran con él y para enviarlos a predicar" (Mc 3,13-14 y par.), "a los apóstoles que había elegido" (Hech 1,2). La llamada de Jesús "los hizo apóstoles" (vocación de los apóstoles que incluye "llamada" y "envío"), porque su nueva identidad, su razón de ser era la misión específica de predicar (Objetivo que confirmará el Resucitado: Mt 28,20) Aquí, y en las reiteradas llamadas y envíos que Jesús hizo en su vida (cf. Mc 6,7; Mt $10,5 ;$ Lc 10,$1 ;$ Jn $13,20 \ldots)$, se encuentra el núcleo de la futura Iglesia misional, el anticipo y base de la esencia misionera del nuevo pueblo de Dios. La evangelización es la finalidad de la llamada; se trata de un llamamiento misional, no solo para que los llamados se salven, llamada a la conversión, dimensión individual), sino para ser enviados a evangelizar y a predicar la salvación de todos (llamada misional, dimensión eclesial o comunitaria).

La acción de Jesús durante su ministerio público se confirmará definitivamente en el envío que hace el Resucitado (cf. Mt 28,18s; Jn 20,21).

30 En las vocaciones que tienen a Jesús por sujeto, podemos ver de nuevo la íntima relación de "llamada" y "misión" cono elementos constitutivos de la vocación. 
Ahora se cumple cabalmente el programa de Mc 3,14, y se dota a los enviados de los medios necesarios para realizar su misión: el Espíritu Santo (cf. Jn 20,22; Lc 3,16; Hech 1,5.8) y la asistencia indefectible del mismo Señor: "Yo estoy con vosotros todos los días hasta el final de los tiempos" (Mt 28,20).

Jesús, El Enviado, constituye a otros en enviados. Aquí radica la vinculación existente entre el ser y el obrar del apóstol enviado y Jesús mitente. Lucas y Juan ofrecen otra variante de lo mismo al identificar la palabra del apóstol con la aceptación de Cristo y del Padre que le envía a él: "Quien escucha a vosotros, a mí me escucha; quien os rechaza a vosotros, a mí me rechaza; y el que me rechaza a mí, rechaza al que me ha enviado" (Lc 10,16; Jn 13,20).

Desde la misión, que confiere la potestad, queda constituido el apóstol.

2.2. Los primeros pasos de la teología: misión y configuración del ministerio

\subsubsection{Los primeros teólogos}

Desde el principio, los Padres apostólicos y los escritores eclesiásticos asignan a la Iglesia la tarea de continuar la misión de los apóstoles, todavía muy cercanos a ellos en el tiempo. La misión de los apóstoles era algo muy vivo y referencia indiscutible en la primera generación post-apostólica. La Iglesia del siglo II estaba fuertemente marcada por la misión y totalmente volcada hacia ella en un contexto abrumadoramente pagano o no cristiano. El foco de esta Iglesia era la misión hacia afuera de ella, hacia un mundo que había que evangelizar, no la problemática interna a la misma Iglesia ${ }^{31}$. Esta Iglesia misionera enarbola como baluarte la tradición, es decir, la fidelidad a la herencia recibida, que se convertirá en cri-

31 Va a ser más tarde cuando la problemática se concentre en los ministerios intraeclesiales. "La teología pronto perdió la perspectiva adecuada que viene sugerida por el vínculo entre los ministerios y la estructura de la asamblea eucarística.., la comprensión de estas órdenes como realidades relacionales que sólo tienen sentido en su interdependencia de la comunidad fue sustituida por un planteamiento que las ve como ministerios individuales" (I.D. ZIZIOULAS, o.c., 235-236). 
terio discernidor de la ortodoxia. Por tanto, la categoría teológica que justifica la existencia del ministerio en la Iglesia es la misión.

La misión genera ministerios múltiples en la primera Iglesia, comenzando por Hech 6,1-7 en la elección de los Siete. Aflora aquí espontáneamente el dinamismo ministerial puesto en marcha por la misión.

Clemente, en la "Carta Primera a los Corintios" (ha.95-96), ahonda teológicamente en el ministerio, cuya raíz profunda pone en la Trinidad, y lo fundamenta en la misión concedida por el mismo Señor a los apóstoles y, por medio de éstos, a sus sucesores. Clemente ha sido llamado "el gran teólogo de la misión"32 y del dinamismo de la misión que se transmite del mitente al enviado, de donde su énfasis en Jn 20,21. La estructura ministerial se organiza a partir de la categoría de la misión. El ministerio eclesial tiene un origen divino y una finalidad de servicio.

Hipólito de Roma, en su célebre "Traditio apostolica", no se limita a la disciplina litúrgica de la Iglesia sobre los ministerios ordenados, sino que señala además las directrices que debe seguir la comunidad cristiana para ser fiel a la tradición-misión apostólica, en función de lo cual se organiza el ministerio ordenado.

Jerónimo sostiene una tesis que no deja de ser llamativa: el nacimiento del episcopado monárquico se debe a la necesidad de superar el cisma o las escisiones dentro de la Iglesia (cf. 1Cor 1,11-13), para lo cual se elige a uno de los presbíteros que se sobrepusiese a los demás en el cuidado de la Iglesia ${ }^{33}$. Por tanto, se detecta en Jerónimo una preocupación más pastoral-misional que una meramente estructural del ministerio dentro de la Iglesia.

En resumen: puede decirse que la categoría teológica de la misión es la dominante en la primera teología a la hora de fundamentar el ministerio; éstos, como ocurrió ya en la era apostólica(los Siete), van apareciendo a medida que la misión de la Iglesia los hace necesarios. Están, pues, supeditados a la misión 34 .

32 R. ARNAU GARCIA, Orden y ministerios, BAC, Madrid 2001, 70. Cf. CLEMENTE ROMAND, Primera Carta a los Corintios, 42 y 44.

33 "In toto orbe decretum est, ut unus de presbyteris electus superponeretur caeteris, ad quem omnis ecclesiae cura pertineret, et schismatum semina tollerentur" (JERONIMO, In Tit. 1,5: PL 26,562). Por tanto, la razón última es de tipo pastoral o misional, pues la unidad de la Iglesia está en peligro.

34 Aludimos ahora tangencialmente a la participación de los misionados o del pueblo en la 


\subsubsection{Hacia una comprensión eucarística de la misión}

La fuerte atracción que la eucaristía ejerce sobre la misión ha dejado también huellas en la primera Iglesia, aunque no fuera el enfoque predominante como acabamos de ver.

La Didaché, donde se nos habla de obispos y diáconos, se presenta la eucaristía con un puesto especial en la misión de la Iglesia. Se vincula al obispo especialmente al culto, asumiendo progresivamente el cometido ministerial y litúrgico que hasta entonces desempeñaban los profetas. La "Didaché" se ocupa más de la Iglesia "ad intra" que de la Iglesia "ad extra".

Por su parte, Clemente Romano hace referencia a la eucaristía desde la perspectiva de a quién corresponde la presidencia de la misma, que él hace recaer sobre el presidente de la comunidad, por tanto, sobre el obispo ${ }^{35}$.

Ignacio de Antioquía asignaba a la jerarquía la competencia fundamental de convocar a la Iglesia en torno al "único altar", es decir, la eucaristía ${ }^{36}$, presidida por el obispo o su delegado ${ }^{37}$. La celebración eucarística convoca en torno al altar a la Iglesia en su totalidad. Seguimos en un contexto muy intraeclesial.

Para Hipólito de Roma, el obispo ejerce el ministerio sacerdotal básicamente en la acción litúrgica; ser sumo sacerdote y ser sumo liturgo son términos unívocos que expresan la realidad eclesial del obispo. El criterio para establecer la naturaleza del obispo y del presbítero se centra en el sacrificio eucarístico ${ }^{38}$, un planteamiento sacerdotal-eucarístico, lo que va a repercutir en la concepción del sacramento del orden hasta que el Vaticano II haga el planteamiento a partir de la misión.

Como consecuencia, como escribe un teólogo actual, "el oficio del obispo en la Iglesia primitiva es esencialmente el de presidente de la asam-

elección (que no en la consagración) del ministro, como testimonian la "Didaché", Clemente Romano, Cipriano, Tertuliano, Hipólito... Testimonios diversos al respecto en R.ARNAU. GARCÍA, 0.c., 8B-93; Id. "Sobre la participación del pueblo en la elección de los ministros" en Anales Valentinos 8 (1978)331-354. Puede consultarse además J. I. GONZÁLEZ-FAUS, Ningún obispo impuesto. Las elecciones episcopales en la historia de la Iglesia, Sal Terrae, Santander 1992.

35 CF. Primera Carta a los Corintios, 40,1-5.

36 Cf. Magn. VII, 1-2.

${ }^{37}$ Cf. Esm. VIII, 1 .

38 Cf. Traditio apostolica, nn. 3 y 7. 
blea eucarística"39. Sin asentir plenamente a esta tesis, sí podemos ver cómo se percibe aquí un movimiento que se va a acentuar con el tiempo: comienza un estrechamiento de la misión, que progresivamente va gravitando sobre la eucaristía y los ministerios referidos a ella, por tanto, de claro tinte intraeclesial, y con un recorte de los ministerios más misionales hacia fuera de la Iglesia. La escolástica reforzará esta línea, que va a ser predominante en el segundo milenio hasta los umbrales del Vaticano II.

\subsection{Concentración eucarística del ministerio eclesial}

La escolástica se va a caracterizar por la concentración eucarística de la misión a través, sobre todo, del ministerio ordenado, y esta herencia dominará el larguísimo periodo que va de la patrística hasta la reforma protestante. Un exponente capital de esta postura es la fundamentación en la eucaristía de la razón de ser del sacramento del orden, con el énfasis consiguiente en la noción de sacrificio. Es, por tanto, un planteamiento claramente intraeclesial y escasamente misionero, con notable pérdida del impulso evangelizador hacia "ad extra" que caracterizó a la Iglesia de los primeros siglos. De esta forma, se diluía la objetividad bíblica y patrística de la misión y su relación con el ministerio.

\subsubsection{Representantes significativos}

Isidoro de Sevilla, que influyó de manera decisiva en los maestros escolásticos, acentúa el planteamiento eucarístico, que es tomado como el punto inicial para fundamentar el ministerio de la Iglesia, otorgándose al ministerio una concepción fundamentalmente sacerdotal ${ }^{40}$.

Pedro Lombardo, el maestro y guía académico de la escuela, establece también la vinculación entre la eucaristía y el sacramento del orden y de todas las órdenes nacidas del sacramento. Su concepción sobre el orden está subordinada a la eucaristía. Los sacerdotes (incluye obispo y presbítero) son los encargados de conferir lo sagrado, su finalidad especial es consagrar y santificar ${ }^{41}$.

\footnotetext{
39 I.D .ZIZIOULAS, o.c., 264.

40 Cf. sobre todo De ecclesiasticis officiis, cap.V.

41 "Presbyteri sacerdotes vocantur, quia sacrum dant" (Sententiarum libri quator, IV, d.24,
} 
Tomás de Aquino llevará a la cima la orientación eucarística. Considera el orden desde el presupuesto eucarístico. El punto de arranque es la "potestas ordinis" o capacidad para consagrar la eucaristía, con lo que el sacerdote queda definido desde la potestad de ofrecer el sacrificio eucarístico ${ }^{42}$. Cuando establece que hay siete órdenes ministeriales, enseña que cada una de ellos guarda relación con la eucaristía; la superioridad de un orden sobre otro dependerá de su mayor o menor relación con la celebración eucarística ${ }^{43}$.

En lo que Santo Tomás avanza sobre sus antecesores es en la idea de instrumentalidad constitutiva del ministro, éste es hecho por la ordenación instrumento del Señor para actuar en su nombre, de modo especial en la celebración eucarística en la que obra vicariamente gracias a que ha recibido el carácter sacramental que le capacita para actuar "in persona Christi", único sacerdote de la nueva alianza ${ }^{44}$.

La mayor parte de los textos en los que Tomás aduce el "in persona Christi" los refiere al sacerdote como ministro de la eucaristía; lo mismo debe afirmarse del sacerdote actuando "in persona Ecclesiae" 45.

\subsubsection{El testimonio de la liturgia}

La concentración eucarística del ministerio eclesial perdura tenazmente y permea a la Iglesia, lo que puede mostrarse desde diversos registros con el lenguaje peculiar de cada uno de ellos. Es el caso de la liturgia.

Cuando los diversos sacramentarios existentes tratan de la ordenación del presbítero, resaltan en el rito gestos bien significativos. Se da, por una parte, la investidura de la casulla, que tiene clara referencia eucarística como distintivo del presbítero que lo diferencia del diácono, manteniendo siempre con este signo una referencia vinculante al sacrificio eucarístico.

q.9). "Sacerdos a sacrando dictus est; consecrat enim et sanctificat" (Ibid.). Sacerdocio para el culto, afecta por ígual al obispo y al presbítero en virtud de la "potestas ordinis".

42 Cf. Summa Teológica, III, q.82; a. 1, 7 y 8. Es claramente deudor de Isidoro de Sevilla, al que cita expresamente, y sigue a P. Lombardo.

43 Cf. Summa Teológica. Supplementum, q.37. Esta práctica la asumirá el concilio de Florencia: DZ 1326.

${ }^{44}$ Cf. Summa Teológica, III, q.22; q.78,a. 1, respondeo; q.82, a.2, ad 2; a.3, respondeo; a.7, ad 3.

45 Cf. Summa Teológica, III, q.64, a.8, ad 2. 
Ambas ideas se expresan claramente en la oración consecratoria del obispo ordenante, donde se enfatiza la necesidad de ministros que ofrezcan el sacrificio de la salvación. Al gesto de la casulla, debe añadirse la rúbrica de ungir las manos del ordenando con el crisma, otra forma elocuente del sesgo eucarístico. Téngase, además, en cuenta el momento de la liturgia de la ordenación en la que se da la entrega de los instrumentos, en el caso del presbítero la patena con pan y el cáliz con vino, significando expresivamente que se designa al ordenado para ofrecer el sacrificio a Dios y para celebrar la misa.

Lo expuesto referente al presbítero puede aplicarse, "mutatis mutandis", a los otros ministerios ordenados. De esta forma, se contribuye, visto ahora desde el registro litúrgico, a convertir la eucaristía en la nota primordial de la definición del ministerio eclesial.

Este era el panorama dominante. "Al margen de la comunidad eucarística no se producía ninguna ordenación para los ministerios fundamentales y estructurales de la Iglesia"46. Se establece una conexión orgánica entre la eucaristía y el ministerio. Los ministerios que no tenían el culto como nota específica quedaban en los márgenes, con lo cual se producía un estrechamiento de la misión.

\subsubsection{Edad Media: la eucaristía desplaza a la Iglesia}

Varios factores contribuyen a ello, además de la teología escolástica a la que nos acabamos de referir. Hay que tener también en cuenta hechos teológicos importantes como las teorías heterodoxas de la época sobre la eucaristía a las que había que hacer frente (cf. Berengario como referente importante). Por tanto, son varios fenómenos los que explican que en la Edad Media se operara un deslizamiento terminológico o lingüístico que lleva en su entraña un giro teológico. En la Iglesia antigua y durante el primer milenio, el "verdadero Cuerpo de Cristo" era la Iglesia, mientras que el "Cuerpo místico de Cristo" era la eucaristía. Ahora se invierte este uso linguístico y el "Cuerpo verdadero" pasa a ser la eucarístia y el "Cuerpo místico" la Iglesia ${ }^{47}$. Este uso lingüístico sigue en vigor. La eucaristía desplaza a la Iglesia.

46 I.D. ZIZIOULAS, o.c., 35.

${ }^{47} \mathrm{Cf}$. el estudio decisivo al respecto de H .DE LUBAC, Corpus Mysticum, Paris 1949, 80- 


\subsection{Trento: respuesta a Lutero desde la teología escolástica}

\subsubsection{Ataque (Lutero) y reacción (Trento)}

Trento sanciona fundamentalmente en el plano del magisterio lo que había enseñado la teología escolástica. El peso de Trento sigue gravitando sobre el tema de la misión de la Iglesia hasta el día de hoy.

Trento fue una reacción ante el ataque y peligro que atentaba a la Iglesia, desgarrada internamente por la Reforma. Los responsables de aquella solemne asamblea salieron al paso con la teología escolástica. Lutero, en su planteamiento del ministerio, eludió enfática y tenazmente la relación entre el sacerdocio y la eucaristía, y lo centró en la predicación como obligación específica del ministro. Había que acudir a este reto subversivo.

La respuesta netamente escolástica de los teólogos tridentinos les llevó a quedar anclados en un pasado secular que había iniciado ya su ocaso. Si hubieran sido capaces de volver la mirada a la Iglesia primitiva y a la patrística en su planteamiento de la misión de la Iglesia, quizá sus planteamientos hubieran sido distintos. Pero no se emprendió ese camino y se siguió metodológicamente el de responder punto por punto a las tesis de Lutero. Consecuencia de ello fue que su horizonte quedara temática y metodológicamente recortado.

Volvamos ahora a Lutero. Un punto central de su ataque es el sacramento del orden sostenido por la Iglesia romana ${ }^{48}$ con su estrecha vinculación a la eucaristía. Lutero ataca frontalmente a la escolástica que sostenía la relación del orden con la eucaristía, rechazándolo en términos absolutos y extremadamente duros. El rechazo de Lutero lo basa en que no halla fundamento en la Escritura ${ }^{49}$, atribuyendo la decisión a la denostada Roma.

Por otra parte, Lutero rechaza la relación entre sacerdote y sacrificio, otro de los soportes escolásticos para definir el sacerdocio de 'la Iglesia.

135. Dato importante: Para Pablo, "la Iglesia o los fieles son el Cuerpo de Cristo" (cf. 1 Cor $3,17 ; 12,27)$.

${ }^{48} \mathrm{Cf}$. sobre todo De captivitate babylonica Ecclesiae y De instituendis ministris Ecclesiae.

${ }^{49}$ Llama la atención que Lutero se apoya ahora en los teólogos escolástico a los que tanto fustiga en la tesis sostenida por éstos de que Jesucristo determinó puntualmente todos los elementos que constituyen el sacramento. Lutero no halla todos los elementos en el Nuevo Testamento. 
Lutero propone la creación de ministros de la palabra y acusa duramente a la Iglesia romana de crear "sacrificadores" 50 . A estas tesis hizo frente Trento por la extremada gravedad que encerraban.

La posición de Trento frente a Lutero quedó cautiva de su propia metodología -dar respuesta punto por punto a los temas planteados por la Reforma-, lo que surtió un doble efecto: primero, se movió en el horizonte parcial y limitado de los planteamientos reformistas; segundo, al contrarrestar a Lutero con la teología escolástica, reforzaba (ahora magisterialmente) la postura escolástica sobre la comprensión eucarística del ministerio. Continuando una larga tradición, Trento propone como nota constitutiva del sacerdocio ministerial, a partir de la Última Cena, la potestad de consagrar y de ofrecer el Cuerpo y la Sangre de Cristo (cf. DZ 1764,1771 ), con lo que parte de la vinculación del sacerdocio al sacrificio (cf. DZ 1740. 1752. Aunque no sin una fuerte discusión conciliar ${ }^{51}$. El sacrificio eucarístico es el presupuesto necesario para el sacerdocio y, por tanto, éste se define desde la eucaristía. El sacerdote no es un mero ministro de la palabra (cf. DZ 1771), pues ser ministro de la palabra se oponía en Lutero a ser ministro de la eucaristía. Trento concibió al sacerdote desde la eucaristía, no directamente desde la predicación que pasó a ser bandera luterana. Esto ha dado pie para decir que la Iglesia romana es la "Iglesia de los sacramentos" y la Iglesia luterana es la "Iglesia de la palabra".

Trento recoge un dato justo e importante, pero lo aísla del contexto completo del sacramento del orden. Es verdad que el sacerdocio ministerial en cuanto ministerio de la presidencia de la eucaristía tiene un innegable dimensión sacerdotal, pero el ministerio de la Nueva Alianza no se reduce a la presidencia de la eucaristía, sino que incluye también los ministerios de la palabra y del gobierno de la comunidad, que tienen también carácter sacerdotal. Estos últimos quedaron en la sombra debido al talante polémico que el concilio tridentino adoptó frente a la Reforma.

${ }^{50}$ Cf. De instituendis ministris Ecclesiae.

51 Cf. E. ROYON, Sacerdocio: ¿culto o ministerio?, Madrid 1976, 65-79. 


\subsubsection{Con Trento...y más allá de Trento}

La huella de Trento ha sido profunda y duradera en lo referente a la relación ministerio eclesial-eucaristía, misión eclesial-eucaristía, "Sacerdos ad cultum". Pero pronto se vio, por lógica interna a la teología, que el ministerio no se puede ejercer circunscribiéndolo al "corpus eucharisticum", sino que se extiende también al "corpus mysticum" que es la Iglesia, con todas las obligaciones pastorales inherentes al cometido eclesial y sacerdotal. Tan real es la potestad sobre el "cuerpo verdadero de Cristo" (eucaristía) como la potestad sobre el "cuerpo místico" (pueblo de Dios), por lo que se deben tener en cuenta aquellos momentos institucionales en que Cristo confirió a los apóstoles la potestad sobre la Iglesia y sus múltiples cometidos. La escolástica y Trento a la zaga dejaban descubierto un enorme espacio que compete al ministerio, lo cual ha creado un cierto malestar en la teología a la hora de abordar el ministerio eclesial y la misión integral de la Iglesia. Un teólogo actual se hace eco de este malestar generalizado: el privilegio que Trento da a la eucaristía, ¿no corre el peligro de minimizar incluso el carácter decisivo y permanente del don bautismal, e incluso el sacerdocio común que brota de ahí?52.

Hemos dicho antes que la huella de Trento es duradera. Un cierto indicio de ellos puede percibirse incluso en algunos pasajes del Vaticano II, pero que no tienen el sentido de Trento si se leen en el conjunto de la doctrina conciliar. Dirigiéndose a los presbíteros, el Vaticano II presenta la eucaristía como centro y raíz de toda su vida y fuente de la caridad pastoral que abarca toda su acción ministerial (cf. PO 14b). Nada que objetar a esta reflexión conciliar en lo que afirma, pero sin olvidar el mandato evangelizador del Señor y su significado central para la vida y actividad del presbítero, punto en el que el Vaticano II es suficientemente explícito. En otro pasaje, se recuerda a los presbíteros el servicio que deben prestar en la "obra de la santificación" (PO 5a), pero también el Vaticano II dice reiteradamente que la acción santificadora no agota el ministerio presbiteral. También afirma el concilio que la eucaristía es el "principal ministerio" de los sacerdotes (PO 13c); principal no puede equivaler a exclusivo o integral.

52 Cf. B. SESBOÜÉ (Dir), Historia del dogma, III, Secretariado Trinitario, Salamanca 1996, 230. 
Parejas consideraciones pueden hacerse a propósito de PDV cuando afirma que "para el sacerdote, el lugar verdaderamente central, tanto de su ministerio como de su vida espiritual, es la eucaristía (n. 26c), o cuando dice que "los sacerdotes, por su condición de ministros. de las cosas sagradas, son sobre todo ministros del Sacrificio de la Misa" (n. 48b). En otro lugar, Juan Pablo II repite la tesis tradicional de la mutua vinculación entre el sacrifico eucarístico y el sacerdocio cristiano ${ }^{53}$.

En una reflexión teológica, parece ser que lo que está en juego y no siempre se acierta a expresar adecuadamente es la dimensión integral del ministerio y de la misión de la Iglesia, la consideración de este ministerio y misión en la pluralidad de formas que adopta para responder a las fuentes de la revelación sin sacrificar y quizá sin priorizar indebidamente una forma ministerial sobre otras. Esto es lo que en mi opinión está en el fondo del Vaticano II, que ha dado un gran paso en esta dirección. En efecto, el Vaticano II, en el conjunto de su magisterio sobre el ministerio y la misión, ha restablecido el equilibrio entre los "tria munera" tanto sacerdotales como eclesiales: el "munus" profético, sacerdotal y real, superando el monopolio sacerdotal y, de esta forma, la concentración eucarística del ministerio. Con el Vaticano II vemos claramente los límites del planteamiento escolástico-tridentino centrado en la eucaristía y, en lugar de partir de la referencia a la eucaristía como sacrificio, se parte de la misión apostólica, en cuyo ámbito se sitúa lógicamente la eucaristía, pero sin que ésta totalice la tarea apostólica de la Iglesia y del ministerio ordenado, y abriéndose así a las diversas vertientes de la misión apostólica.

Tras las huellas del Vaticano II, también PDV va más allá de la postura tradicional y amplia. el horizonte ministerial al abrirlo al "mandato de anunciar el Evangelio" al mismo tiempo que "renueva cada día el sacrificio de su cuerpo entregado y de su sangre derramada por la vida del mundo" (n. 1c). Tan mandato misional es continuar haciendo lo que el Señor hizo en la Última Cena como el mandato de anunciar el Evangelio a todos los pueblos. En este sentido, Juan Pablo II afirma tajantemente: "El sacerdote es, ante todo, ministro de la palabra de Dios; es el ungido

53 "La eucaristía es la principal y central razón de ser del sacramento del sacerdocio" (JUAN PABL0 II, El misterio y el culto a la eucaristía. Carta a todos los obispos de la Iglesia, Vaticano 1980, n.2). El sacramento del sacerdocio vincula ministerio-eucaristía, pero también al servicio del pueblo de Dios que ciertamente incluye a la eucaristía, pero no en exclusiva. 
y enviado para anunciar a todos el Evangelio del Reino" (n. 26b: subrayado en el original; se ve, no obstante, el contraste con lo afirmado en 48b).

Después de este esbozo de trayectoria teológica sobre la misión-ministerio eclesial, estamos en condiciones de abordar la Iglesia vista desde la misión al hilo de la teología actual y el giro que ello significa.

\section{Viraje del Vaticano II: la Iglesia vista desde la misión}

Trece siglos van de Isidoro de Sevilla al Vaticano II, trece siglos de comprensión eucarística del ministerio eclesial. El Vaticano II representa un viraje fundamental con la vuelta al planteamiento bíblico-patrístico y su alejamiento del planteamiento escolástico.

\subsection{El giro conciliar}

En el amplio abanico de su doctrina ministerial, el Vaticano II recupera la dimensión eclesial y articula en torno a ella su reflexión como eje y centro, no en tomo a la dimensión eucarística. Ha emprendido con ello derroteros nuevos que parten de la misión. Se ha pasado de la formulación eucarística de la institución a la formulación misional de la misma. No es que este concilio ignore la relación Iglesia-eucaristía (ya presente en Pablo: 1Cor 10,16-17 y constante en toda la tradición: LG 7), pero avanza en esta idea hablando del efecto eclesial de la eucaristía, pues en ella se edifica la unidad de la Iglesia y de los creyentes (cf. LG 3). Es una perspectiva a la vez sacramental y eclesiológica.

El sacramento del orden tiene como finalidad el servicio al pueblo de Dios en su pluralidad de necesidades. Ahora se ha pasado de la vinculación ministerio-eucaristía a la vinculación ministerio-servicio al pueblo de Dios, que ciertamente incluye a la eucaristía, pero no en exclusiva.

La misión pasa a ser elemento principal constitutivo del ministerio eclesial. "El concilio Vaticano II, y la documentación eclesial que emana del mismo, ha provocado un vuelco en la antigua fundamentación eucarística del sacramento del orden al apoyarlo en la misión que arranca del Padre por Cristo" 54 , a partir del texto básico de Jn 20,21.

54 R. ARNAU-GARCIA, O.c., 178. 
El giro del Vaticano II se percibe y valora mejor si se tiene en cuenta la situación que llega hasta él. Es significativo que en una obra como el "Dictionnaire de Théologie Catholique" no figure el artículo "Mission"; esta laguna se observa en la eclesiología de la enseñanza escolar del siglo XIX: "En una época que es activamente misionera, está ausente en los tratados escolares el dinamismo de la misión, que se expresa en los fundadores de institutos misioneros" 55 , tan abundantes en ese siglo.

Ya hemos dicho que la Iglesia es "extrovertida", que "no existe en sí" o "por sí misma", sino para el mundo56. La Iglesia tiene naturaleza relacional por su origen y por su finalidad. El único modo de misión eclesial es la encarnación, la implicación existencial en el mundo. La misión no consiste, ante todo, en que la Iglesia se dirija al mundo (Iglesia y mundo), sino que está implicada y llena de compasión por el mundo (Iglesia en el mundo, Iglesia samaritana) ${ }^{57}$.

El principio de la misión pasa a ser en el Vaticano II el que informa y preside a toda la Iglesia. Ésta, como Cristo (cf. Jn 10,36), es llamadaenviada al mismo tiempo; también como Cristo (cf. Mc 3,14; cf. 6,7; Lc 6,$13 ; 10,1 \mathrm{~s}$ ), debe llamar para enviar ${ }^{58}$. Sin misión, no hay vocación bíblica como hemos mostrado más arriba; sin misión, no hay Iglesia porque le faltaría la razón de ser.

El viraje del Vaticano II con relación a Trento en la concepción del ministerio es del todo decisivo para comprender la Iglesia del Vaticano II por cuanto el ministerio no es sino "la Iglesia en acción", su vertiente operativa. Pues bien, "es la realidad de la misión la que constituirá el punto de partida para la inteligencia del ministerio de la Iglesia"59.

55 Y.-M.CONGAR, "Eclesiología. Desde S. Agustín hasta nuestros días" en M. SCHMAUS-A. GRILLMEIER- L.SCHEFFCZYK (Dirs), Historia de los dogmas, Tomo III, Cuaderno 3c-d, BAC, Madrid 1976, 286-287.

56 Es la orientación fundamental y novedosa de GS: la Iglesia existe en el mundo, es inconcebible sin el mundo, de donde el titulo de la Constitución pastoral: Iglesia en el mundo, no Iglesia y mundo, orientación advertida por todos los comentaristas "Sacramentum mundi".

${ }^{57}$ Cf. I.D. ZIZIOULAS, O.c., 238.

58 Ya hemos indicado que el binomio llamado-enviado forma un bloque, no son dos términos yuxtapuestos, y así aparece con frecuencia en el Vaticano II: LG 28a; SC 5a; PO 7a; 12b; 17e. Algo lógico en un concilio que se autodenomina pastoral (Cf. Juan XXIII, Discurso de apertura del concilio -11 de octubre de 1962-, y Pablo VI, Discurso de clausura del concilio -7 de diciembre de 1965).

59 K. DENIS, "La teología del presbiterado desde Trento al Vaticano II" en AA.VV., Los 


\subsection{Magistral planteamiento ministerial del Vaticano II}

El ministerio eclesial recibe del Vaticano II un tratamiento magistral, supera toda reduccionismo, establece el anhelado equilibrio entre todas sus manifestaciones (profética, sacerdotal y real) y otorga a cada una de las manifestaciones su peculiaridad y función específica, todo ello con una sólida cobertura teológica. Es éste, quizá, el aporte ministerial más importante del concilio. El principio rector y el motor de todo ello se encuentra en la misión.

Aludamos sucintamente a un dato básico: el Vaticano II puede leerse en clave ministerial, pues ésta lo atraviesa transversalmente ${ }^{60}$. Un ministerio al servicio de la misión, un concilio ministerial y, por tanto, pastoral o abocado a la misión.

El Vaticano II aborda con mano maestra la tríada tradicional del ministerio, con referencia particular al obispado y al presbiterado. Nos vamos a referir al ministerio ordenado por ser éste por antonomasia la expresión de la "Iglesia en acción". Cada miembro de la tríada ordenada recibe la correspondiente fundamentación teológica y su peculiar competencia, sin sacrificar ninguna a las demás. Queda desautorizado cualquier monopolio ministerial. A la doctrina conciliar adjuntaremos lo que enseña PDV por ser una glosa y un desarrollo autorizado del Vaticano II.

Un texto conciliar puede fungir como punto de partida: "Para apacentar el pueblo de Dios y acrecentarlo siempre Cristo Señor instituyó en su Iglesia diversos ministerios, ordenados al bien común de todo el Cuerpo" (LG 18a; cf. 1Cor 12,4-6). Por tanto, los diversos ministerios son obra de Dios y tiene una finalidad misional en cuanto servicio al pueblo de Dios. Este cuadro sintético refleja el panorama conciliar:

* Ministerio de la Palabra (profético): Obispo: LG 25 en común con el Papa; CD 12 en su Iglesia particular;

Presbítero: PO 4;13b; PDV $26 b$.

sacerdotes, Madrid 1969, 234. Punto de vista sostenido por teólogos como Congar, Kasper, Schillebeeckx, Moltmann, Ratzinger...

${ }^{60}$ Los documentos conciliares principales son eminentemente ministeriales: Ministerialidad de la Iglesia (LG; GS; SC; AG),. ministerio petrino y episcopal (LG, cap.III; CD), ministerio presbiteral (LG 2á; PO; OT), ministerio laical (LG cap. IV; AA), ministerio de la vida religiosa (LG cap.VI; PC), ministerio del diácono (LG 29), ministerio ecuménico (UR), ministerio de los medios de comunicación (TM), ministerio de la educación cristiana (GE). 
* Ministerio de la santificación(sacerdotal): Obispo: LG 26; CD 15 Presbítero: PO 5;13c;PDV 26c-e

* Ministerio de gobierno (real): Obispo: LG 17; CD 16 Presbítero: PO6;13d; PDV $26 f$

El ministerio episcopal (primer analogado y pauta de todo ministerio ordenado por ostentar la capitalidad eclesial que recae sobre el obispo porque en él se concentra de modo sacramental la misión y sucesión apostólica), se fundamenta en la misión (cf. LG 19; CD 2; AG 3) y se recibe en el sacramento único del orden del cual participan, cada uno a su modo, los otros ministerios ordenados. Único ministerio sacramental con base cristológica en la misión apostólica y con finalidad eclesial en la edificación del Cuerpo de Cristo.

El Vaticano II no establece jerarquía entre las tres funciones ministeriales (profética, sacerdotal y real) de modo que sitúe a una de ellas por encima de las otras, sino que, con buen criterio y superando la tradición heredada, expone la consistencia y competencia de cada una de ellas, la armonía y complementariedad entre ellas, pues son tres ámbitos inseparables del ministerio por lo que solo cabe distinguirlos inadecuadamente. Lo que sí resalta el concilio con fuerza es la necesidad de cada una de ellas para servir al pueblo de Dios. Es la teología la que ha planteado si hay una función que contiene a los otras dos y puede así integrarlas; a este punto se dan diversas respuestas en la teología actual ${ }^{61}$. En la perspectiva del concilio, el ministerio eclesial es un todo que remite como tal a su origen divino, que se expresa en tres realizaciones de ese único ministerio ${ }^{62} . \mathrm{Si}$ hubiera que optar por una función que hiciera justicia por igual a las tres formas o realizaciones, sería, en la línea del Vaticano II, la de pastor. En todo caso, y esto en una perspectiva histórico-funcional-pedagógica (no ontológica), cabría anteponer el ministerio de la Palabra como requisito para acceder a los ministerios sacerdotal y de gobierno.

61 Una visión panorámica puede verse en G. GRESHAKE, Ser sacerdote. Teología y espiritualidad del ministerio sacerdotal, Sígueme, Salamanca 1995, 83-88 (con bibliografía).

62 Cf. al respecto el texto tan perfilado de LG 28a: "El ministerio eclesiástico, de institución divina, es ejercido en diversos órdenes por aquellos que ya desde antiguo vienen llamándose obispos, presbíteros y diáconos". Cf. Dz 1765.1776. 


\subsection{La Iglesia se autocomprende desde la misión}

\subsubsection{Escritura y Vaticano II}

Comencemos por la Escritura. La misma terminología habla a favor de nuestra tesis: Ekklesia significa "convocada-enviada". La Iglesia nace con la misión y para la misión. No hay Iglesia sin Pentecostés, donde nace en cuanto "enviada", al mismo tiempo que es capacitada para la misión que se le confía. La comunidad de los seguidores de Jesús es desde el primer momento misionera y debe decir con Pablo: "Pobre de mí si no anunciara el Evangelio!" (1Cor 9,16). La Iglesia es desde el principio una "fraternidad apostólica" (cf. AG 2,5-6; AA 1), se caracteriza por la misión. Iglesia de Jesús para la causa de Jesús, "por él y por el Evangelio" (Mc 3,$35 ; 10,29$ ). Con la asistencia del Espíritu Santo (cf. Hech 1,5.8.22; 2,32; 3,$15 ;$ Jn 1,33; 3,5-6; Lc 3,16) ${ }^{63}$ y de su Señor y Fundador (cf. Mt 28,20), la Iglesia naciente asume decididamente la nueva tarea (cf. Hech 2,$32 ; 3,15 ; 4,20$ ), sin arredrarse ante las dificultades (cf. Hech 5,29), en una labor que se prolonga por los siglos (cf. Hech 5,42). De esta manera, la Iglesia encuentra en la labor evangelizadora su objetivo, su gloria y su corona, como bellamente ha expresado PabloVI ${ }^{64}$.

Los evangelios son escritos misioneros que gravitan sobre la tarea misional e impulsan a la comunidad eclesial a tareas siempre nuevas.

La Iglesia es constituida pueblo-puente, tarea en la que había fracasado el Viejo Israel, de cara a todos los pueblos; es comunidad misionera y kerigmática, en definitiva, "pueblo mesiánico" (LG 9b). El centro no es la Iglesia ("para sî"), sino la misión ("para los demás"); medio (sacramento) para un (Evangelio). Por eso el Vaticano II desborda todo "eclesiocentrismo". No es la Iglesia la que define la misión, sino que es la misión la que define a la Iglesia y la hace "sacramento universal de salvación". La

63 Es quizá Lucas quien más resalta esta idea. En Hechos se menciona al Espíritu 42 veces; en el evangelio, 13 veces.

${ }^{64}$ Cf. PABLO VI, Exhortación apost. "Evangelii nuntiandi", nn.13.14.59.60.66... (En adelante $\mathrm{EN}$ ).

Los sinópticos se cierran con un mandato misionero dejado a la Iglesia (Mt 28,19-20; Mc 16,15; Lc 24,47-48). Este dato, conclusión y de alguna manera síntesis de los evangelios, debe ser debidamente valorado. Podríamos decir que así expresa el Señor "sus últimas voluntades", que es su última palabra en su último momento en la tierra. 
Iglesia está marcada por la convicción de ser una comunidad para la misión, como testifican los sumarios de los Hechos de los Apóstoles (cf. 2,42-47; 4,32-35; 5,12-16). Los sinópticos cierran sus evangelios con un compromiso misionero. "La misión apostólica se expresa en términos de "la experiencia de la Iglesia primitiva"”65.

Escuchemos ahora al Vaticano II, una vez escuchada la Escritura, siguiendo también aquí la pauta de la terminología. Es bien sabido que el Vaticano II ha definido a la Iglesia como sacramento en varios registros (cf. LG 1 y 42c; LG 9b; LG 9c; LG 48b y AG 1a) para expresar la misma idea: la Iglesia es sacramento. Por tanto, la Iglesia es medio (instrumento) al servicio de un fin (misión-salvación). Se auto-comprende en estos términos:"La Iglesia ha nacido con este fin: propagar el Reino de Cristo en la tierra para gloria de Dios Padre, y hacer así a todos los hombres partícipes de la redención salvadora y por medio de ellos ordenar realmente todo el universo hacia Cristo" (AA 2a). Para lograr este fin, fue constituida "sacramento". Un medio para un fin, ambos queridos y creados por Dios ${ }^{66}$. La Iglesia es esencialmente servicio (servidora. idea directriz de GS), servicio no como algo añadido a su ser previo, sino como constitutivo de su mismo ser. Por eso, "una Iglesia que no sirve, no sirve para nada" 67 . A partir del Nuevo Testamento, a la sustancia de la Iglesia pertenece el mandato misional otorgado por Jesucristo, un mandato que pertenece a lo absoluto en la Iglesia. Esta es la línea argumentativa del Vaticano II que se va a prolongar y profundizar en el postconcilio.

En efecto, desde esta perspectiva, se explica que la teología actual entienda la Iglesia desde la misión, no la misión desde la Iglesia. Los textos bíblicos recurrentes se refieren al envío que hace Jesucristo en los apóstoles haciéndoles partícipes de su propia misión y continuándola así en la historia (cf. Jn 20,21; 17,18; Mc 3,14; Mt 28,18). El Vaticano II ha visto que la misión constitutiva otorgada por Cristo a los apóstoles es el fundamento de la Iglesia y del ministerio apostólico (cf. LG 20), la Igle-

65 J.L.McKENZIE, "El Evangelio según Mateo" en R. E. BROWN- J.A FITZMYER- R.E. MURPHY (Dirs), Comentario Bíblico San Jerónimo, III, Cristiandad, Madrid 1972, 292.

66 "En el plan de Dios, tiene categoría de fin, mientras que el ministerio jerárquico es un medio en vistas a ese fïn" (A. ANTON, "Eclesiología postconciliar" en R. LATOURELLE [Ed], Vaticano II: Balance y perspectivas. Veinticinco años después [1962-1987], Sígueme, Salamanca 1989,289$)$.

67 Título de la obra del obispo J. GALLLT, Sal Terrae, Santander 1991. 
sia se sigue sustentando en el hecho de que Cristo llama, envía y dota de autoridad a los llamados-enviados para servir al pueblo de Dios y a toda la humanidad: es la dimensión eclesial de la vocación.

Esta opción por la misión nos explica por qué el Vaticano II ha abandonado el planteamiento eucarístico del ministerio que llega hasta el mismo concilio y lo ha enfocado por los nuevos derroteros de la misión. Ésta cuenta con el elemento esencial de la eucaristía, pero no se agota en ella, sino que se abre al ministerio profético y de gobiemo como integrantes de la misión. De ahí la importancia de la predicación y del gobierno del que preside la comunidad, porque la preside en todas sus facetas, más aún, preside la eucaristía porque preside la comunidad, no viceversa ${ }^{68}$.

El mandato misional de Jesucristo a los Doce pertenece a lo absoluto de la Iglesia y, como tal, no puede ser alterado; la Iglesia es la responsable de la misión, tanto en su conservación como en su actualización y transmisión" ${ }^{69}$ La Iglesia es "esencialmente misionera" (AG 2a), que misiona y genera y envía misioneros en nombre de Cristo; la Iglesia es sacramento, está al servicio de la misión, se autocomprende desde la misión. Una misión, la de la Iglesia; diversos ministerios para llevarla a cabo (cf texto citado de LG 18a). La grandeza de la Iglesia no reside en sí misma, sino en el tesoro que se ha confiado a ese vaso: Cristo y su causa, de los que es sacramento y servidora. Consecuentemente, "no hay que entender la misión a partir de la Iglesia, sino más bien la Iglesia a partir de la misión"70. El dinamismo evangelizador penetra a toda la Iglesia para transformar a la humanidad desde su interior, siendo "sacramento" y "levadura"71.

\subsubsection{De la Iglesia "communio"(LG) a la Iglesia "missio"(GS)}

Convocada y enviada. Iglesia "misterio-comunión-misión"72. Con esta

68 Punto debatido entre los teólogos: cf. G.GRESHAKE, O.c., 65ss.208- 209.

${ }^{69} \mathrm{Cf}$. DV, cap. II. "Ni los evangelizadores ni la Iglesia son dueños y propietarios absolutos para disponer del evangelio a su gusto, síno ministros para transmitirlo con suma fidelidad" (PABLO VI, EN nn. 15.60).

70 J. MOLTMANN, La Iglesia, fuerza del Espíritu, Sígueme, Salamanca 1978, 26.

71 Cf. Ef 2,18; Rom 1,16; LG 1; PABLO VI, EN n. 19.

72 JUAN PABLO II Ex. apost. Pastores dabo vobis, n 12 ss. Otra formulación: Misterio de comunión trinitaria en tensión misionera" (íbid.). 
trilogía sintetiza magistralmente Juan Pablo II los ejes vertebrantes de la Iglesia del Vaticano II en cuanto "icono de la Trinidad".

"Comunión" y "misión" son dos vertientes fundamentales de la Iglesia. No damos razón suficiente de ella respondiendo a la pregunta: ¿qué es la Iglesia? con el término "comunión" (naturaleza, esencia), sino que debemos responder también a la pregunta: ¿para qué existe la Iglesia? diciendo que existe para la "misión" (quehacer, tarea). Es la lógica teológica que va del ser al actuar ambos elementos constitutivos de la Iglesia. El "estatuto de comunión" genera la "dinámica de la comunión", configurándose así la "eclesiología de comunión" típica del Vaticano II.

Ser (comunión) y actuar (misión) constituyen una única realidad teológica que es la Iglesia. Lo entitativo (comunión) y lo operativo (misión) son inseparables en la definición de la Iglesia y están regidos por el "principio-comunión".

Si alguien preguntare: ¿prioridad del ser sobre el actuar, o viceversa?, equivaldría a decir: ¿prioridad de LG sobre GS, o viceversa? La pregunta se hace desde un falso planteamiento alternativo (o...o) o de una parataxis (no sólo...sino también), pero si partimos del Dios Uni-Trino como lo hace el Vaticano II, es decir, de la Iglesia "icono de la Trinidad", vemos la indisociable relación que existe entre comunión y misión. Es una Iglesia considerada simultáneamente "ad intra" y "ad extra"73 que nosotros separamos metodológicamente para su estudio. La eclesiología del Vaticano II ha logrado el perfecto engranaje de las dos dimensiones de la Iglesia: misterio-comunión (LG) y misterio-presencia histórica para la humanidad (GS). Una Iglesia del amor exodal y gratuito del Padre (cf. Lc 15,20.28; Col 1,22), que la hace salir de sí misma para ser el buen samaritano de la humanidad. "La communio de la Iglesia consiste precisamente -en todos sus niveles- en la realización de la missio, en la responsabilidad asumida con respecto a su misión en el mundo"74. Si olvidamos el "enviada" (el para qué, la misión, la Iglesia "ad extra"), caeremos en el eclesiocentrismo denunciado y superado por el Vaticano II. La misión es un concepto

73 Fue este un giro capital de la eclesiología del Vaticano II: "Ecclesia ad intra y ad extra, que explica la génesis de GS, documento no previsto en la agenda preparatoria del concilio" (cf. G. ALBERIGO (Dir), Historia del Concilio Vaticano II, II, Peeters-Sígueme, Leuwen-Salamanca 2002,318 s.

74 G. GRESHAKE, O.c., 280 (Subrayados en el original). 
clave para entender a la Iglesia, la misión adquiere categoría dogmática. Esto nos explica el porqué la teología actual entiende a la Iglesia a partir de la misión, dicho en términos evangélicos, desde su condición de "sal" y "luz" para los hombres (cf. Mt 5,13s).

Podíamos extendamos en el papel asignado a la misión en toda vocación cristiana y eclesial, tanto genérica como específica, tanto la vocación referida al ministerio ordenado como al no ordenado ${ }^{75}$. O sobre otro dato de carácter histórico-práctico que nos limitamos a aportar adicionalmente como es el papel determinante que juega la misión en el origen, naturaleza y perfil espiritual y pastoral de la diversidad de familias religiosas nacidas en la Iglesia 76.

\subsection{Falsa alternativa: perspectiva misional vs perspectiva eucaristi- co-sacramental}

No debe verse una alternativa entre la perspectiva misional y la eucarística ${ }^{77}$. Ambas son necesarias en la Iglesia, y lo significa con suficiente claridad el rito de la ordenación de sus ministros: en la imposición de las manos se significa la dimensión misional o el envío que se hace del ordenado; en la entrega de los instrumentos se apunta a la dimensión eucarística. A elementos y gestos significantes distintos siguen dimensiones diversas inherentes a la realidad ministerial que se confiere, aunque no se deberían situar al mismo nivel teológico ${ }^{78}$. El Ritual de ordenación

75 Cf. R .SÁNCHEZ CHAMOSO, "La misión, componente teológico de la vocación". 529535.

76 Cf. Ibid, 535-538.

77 Para una panorámica sobre las posturas actuales sobre qué debe prevalecer si el servicio a la eucaristía o a la comunidad, con una propuesta de síntesis que haga justicia a ambas posturas, cf. R. Sánchez Chamoso, Ministros de la Nueva Alianza. Teología del sacerdocio ministerial, CELAM, Bogotá 1993, 446-452. "La eucaristía, sacramento fundamental de la unidad de la Iglesia, es presidida por el ministro de la comunidad. En la presidenciá de la Iglesia está incluida la presidencia de la eucaristía y de las otras acciones básicas a través de las cuales vive, crece y cumple su misión la Iglesia" (P. BLÁZQUEZ, "La relación del presbítero con la comunidad" en COMISIÓN EPISCOPAL DEL CLERO, Espiritualidad del presbitero diocesano secular. Simposio, EDICE, Madrid 1987, 325.

78 Claro que, si recordamos que "la imposición de las manos" es la materia del sacramento del orden, y no "la entrega de los instrumentos (cf. PÍO XII, Const. apost. "Sacramentum ordinis" -30 de noviembre de 1947: DZ.3857-3861-), no se pueden valorar teológica y sacramentalmente ambos signos por el mismo rasero. Prevalece, sin duda, la dimensión misional, se 
actualmente vigente en la Iglesia expresa con claridad la teología ministerial del Vaticano II: dimensión eclesial del ministerio, teología de la misión implícita en la eclesiología del Vaticano II, comprensión del ministerio eclesial desde la dimensión de la misión. Pero, repetimos, la perspectiva eucarística no ha caído en desuso como alguien pudiera concluir precipitadamente. En realidad, la imposición de las manos tiene una valencia inclusiva pues hace del ordenado un enviado a la comunidad con legítima competencia en los "tria munera": pastoreo con el ministerio de la Palabra, con la presidencia y guía de la comunidad y con la santificación por medio de los sacramentos.

El Vaticano II ha logrado magistralmente una visión unitaria del ministerio al que abarca en las tres vertientes del mismo sin exaltar una a costa de las demás ${ }^{79}$. Queda así zanjada la falsa alternativa entre misión y sacramentos, entre servicio al Evangelio y servicio a Dios, presentando a ambos miembros como integrantes de la misión eclesial. ¿No es, por otra parte, la celebración de la eucaristía y la administración de los sacramentos la mejor acción pastoral para construir la comunidad? Esta perspectiva teológica actual se recoge en la expresión afortunadamente en voga: "La eucaristía hace la Iglesia".

refuerza la opción por la misión y la teología de la misión. Pío XII, con la nueva legislación sobre la materia y la forma del orden, ha superado el uso litúrgico-sacramental vigente durante el segundo milenio (expresión de la opción eucarística) para volver al Nuevo Testamento y a los Padres (expresión de la opción misional). Por consiguiente, el giro en la praxis litúrgica rebasa lo meramente ritual y contiene materia teológico-dogmática. "La imposición de las manos solo ha llegado a ser considerada tajantemente como la forma constitutiva de la transmisión válida del ministerio a partir de Pío XII" (W.KASPER "Convergencias y divergencias en la cuestión de los ministerios" en Concilium 74[1972] 111).

79 Cf. R. SÁNCHEZ CHAMOSO, "La misión, componente teológico". 518; Id., Iglesiacomunión e Iglesia ministerial. Comunión-Ministerio eclesial-Presbiterio, IUSI, Caracas 1997, 344-347; G. GRESHAKE, O.c., 83-88.

Se debe insistir en esta idea. Los textos del Vaticano II sacan al ministerio sacerdotal de la estrechez en que había caído por la acentuación unilateral de la función ritual, y muestran que su plenitud de sentido solo imperfectamente puede reproducirse por el concepto de "sacerdote", si se toma este literalmente y sin crítica del Antiguo Testamento y de las religiones. El sacerdocio del Nuevo Testamento se realiza en el culto, en la predicación de la palabra y en la potestad de dirigir; por eso, hay que recurrir para su esclarecimiento a la noción de lo profético y a otras nociones. 


\section{La misión en la encíclica "Redemptoris missio"so}

Esta encíclica es un importante documento del magisterio que incide en nuestro tema de estudio por lo que la presentamos como colofón del mismo. Si en lo que precede ha predominado el planteamiento teológico, en esta encíclica se nos orienta en el plano más pastoral y operativo, más cercano a nuestra realidad concreta y existencial.

\subsection{La misión, urgencia especial hoy y desafio para la Iglesia}

La encíclica comienza señalando que la misión confiada a la Iglesia reviste hoy una peculiar urgencia derivada de que "está aún lejos de realizarse, se halla todavía en los comienzos" (n. 1). Más aún, el número de los que no conocen a Cristo ni forman parte de la Iglesia está en aumento, "desde el final del concilio casi se ha duplicado" (n. 3), y esto interpela a la Iglesia que es de "índole misionera" (n. l).

La evangelización es el servicio primero y especifico que la Iglesia puede prestar al mundo, dirigiéndose a todos (cf. nn. 2.5).El momento actual, frente a ciertas posturas derrotistas, es más propicio: "Dios abre a la Iglesia horizontes de una humanidad más preparada para recibir la siembra evangélica...Los horizontes y las posibilidades de la misión se ensanchan" (nn. 3.30.92) ${ }^{81}$. Ante esta perspectiva, la Iglesia se siente abrumada al tiempo que urgida por la responsabilidad que le incumbe y lo limitado de sus recursos (cf. n. 35). Por eso, es más urgente la colaboración de todos, porque no se puede renunciar a la tarea misional por ser la Iglesia "sacramento universal de salvación" como reiteradamente proclama el Vaticano II.

\subsection{La Iglesia particular ante la tarea misional}

"Redemptoris missio" reflexiona sobre la implicación de cada Iglesia

80 Extractamos ideas expuestas en nuestro trabajo "Iglesia particular y mandato misionero. Estudio de la misión en la encíclica Redemptoris missio" en Misión Hoy 4 (enero-marzo 1995)6-7. (Citaremos la encíclica en la exposición con el número correspondiente).

81 Interesante coincidencia en el modo de ver la situación con Juan XXIII en el celebre Discurso de apertura del Vaticano II frente a los "profetas de calamidades" (nn. 9.10.13). 
particular para no perderse en vaguedades o generalidades. La cobertura teológica la ofrece el Vaticano II con su teología de la Iglesia particular.

La misión evangelizadora ha de ejercerse bajo el lema de la comunión operativa misionera; es una referencia al estilo evangelizador derivado de la naturaleza de la Iglesia y de la misión. La encíclica hace suyas las palabras de Pablo VI: "Una Iglesia particular que se desgajara voluntariamente de la Iglesia universal perdería su referencia al designio de Dios y se empobrecería en su dimensión eclesial"s2.

La encíclica se detiene en concreto en la Iglesia particular. Acentúa, a la zaga del Vaticano II, que "todo ministerio de la Iglesia está contenido en cada Iglesia particular" (n. 48), de donde brota el "compromiso" comunitario y la responsabilidad de cada Iglesia local” (n. 27). Cada Iglesia particular y toda comunidad local es misionera por naturaleza, lleva en su entraña la misión (cf. nn. 49.61.62). Más aún, hay tareas concretas que solo puede llevarlas a cabo la Iglesia particular (cf. nn.52.53.54.82.83).

\subsection{Responsables del mandato misionero}

La Iglesia lleva el distintivo de apostólica por lo que toda ella es responsable y lleva la misión de los apóstoles.

Tras las pistas del Vaticano II, "Redemptoris missio" enumera jerárquicamente a los responsables de la misión. Por eso comienza por el Colegio episcopal, representante eximio de la capitalidad eclesial en cuanto sucesor del "Colegio apostólico". Todos y cada uno de los obispos comparten con el Papa la responsabilidad de la Iglesia y de su misión en el mundo. Muy expresivamente escribe Juan Pablo II: "Mis hermanos obispos son directamente responsables conmigo de la evangelización del mundo, ya sea como miembros del Colegio episcopal, ya sea como pastores de las Iglesias particulares" (n. 63: es literalmente lo enseñado en LG 23).

La responsabilidad misionera corresponde también a la Iglesia particular dirigida por su obispo, y hay que formarla en este sentido: "Toda Iglesia particular debe abrirse generosamente a las necesidades de los demás" (n. 64), es decir, debe convertirse en comunidad misionera.

Pasando a otros niveles, la encíclica insiste de forma significativa en la necesidad de formar a los sacerdotes con espíritu misionero católico (cf. nn.

82. PABLO VI, EN n. 62 
67.68) pero también al Pueblo de Dios o fieles: "La formación misionera del Pueblo de Dios es obra de la Iglesia local, que ha de incluir la animación misionera como elemento primordial de su pastoral ordinaria" (n. 83).

La encíclica termina, dirigiéndose ahora a todos los responsables, saliendo al paso oportunamente de cualquier particularismo (con más celo que solidez teológica, impropio de una Iglesia que se denomina "católica"), que empequeñece la misión (cf. n. 85). Hay que asumir que, en la evangelización todos somos responsables y necesarios, pero nadie debe monopolizar o considerarse el representante más genuino o exclusivo, pues la misión supone un rico intercambio de dones y recursos. Toda la Iglesia da y toda la Iglesia recibe (cf. n. 85).

El Vaticano II ha marcado el camino. Convoca a todos a la única misión (la de la Iglesia), que se lleva adelante por medio de diversos servicios (vocaciones). La Iglesia es operativamente un "cuerpo ministerial", es "toda ella ministerial", una verdadera "comunión de servicios" bajo la acción y dirección del Espíritu; así muestra operativamente su ser entitativo comunional. El Espíritu "unifica a la Iglesia en comunión de ministerio, la provee y gobierna con diversos dones jerárquicos y carismáticos que la embellecen con sus frutos" (LG 4a; AD 4). Culminamos nuestro estudio con estas palabras conciliares: "Este santo concilio desea delinear los principios de la actividad misional y reunir las fuerzas de todos los fieles para que el Pueblo de Dios, caminando por el estrecho sendero de la cruz, extienda por todo el mundo el Reino de Cristo, Señor, que preside los siglos, y prepara los caminos de su venida" ( $\mathrm{AG}$ 1c).

Todo un programa misionero para nuestra Iglesia, grávido de esperanza y de exigencia, una Iglesia que hoy se auto-comprende desde la misión. 